\title{
The prevalence and nature of the use of preconception services by women with chronic health conditions: an integrative review
}

Amie Steel ${ }^{1,2^{*}}$, Jayne Lucke ${ }^{3,4}$ and Jon Adams ${ }^{2}$

\begin{abstract}
Background: There is growing evidence that preconception care may have an important role in preventing short and long term adverse health consequences for women and their offspring. This is particularly the case for women with chronic health conditions due to the rising prevalence of chronic disease in global populations. With this in mind, this paper presents an integrative systematic review of contemporary research outlining the use of preconception services and practices by women with chronic health conditions.

Methods: A search was conducted through PubMed, CINAHL, AMED, and Maternity and Infant Care databases which identified 672 papers examining preconception care and preconception services for women with chronic health conditions. Fourteen papers which were written in English, presented original research, and reported on the prevalence or nature of use of preconception care by women with chronic health conditions were included in the review. Critical appraisal of study quality and thematic categorical grouping of identified papers was undertaken.

Results: Current research evidence, as identified through this review, examines three major topic areas: the prevalence of preconception care practices, use of services and characteristics of users; knowledge of the value and impact of preconception care and availability of preconception services for women with chronic health conditions; and women's attitudes, approaches and experiences of preconception care and preconception services. Prevalence estimates of engagement with preconception care range between $18.1 \%$ and $45 \%$, with most studies focusing on women with type 1 or 2 diabetes. Significant gaps in women's knowledge of preconception care for women with chronic health conditions were also identified. Women with chronic health conditions reported experiencing emotional distress as a result of their engagement with preconception care services. They also commonly described feeling a need to employ discipline to comply with preconception care programs, and experiencing a fear of pregnancy complications.
\end{abstract}

Conclusion: Future research requires a broad and sophisticated approach to research design and analysis, improved consideration of temporal changes to women's health behaviour, representative samples to more effectively inform health policy, and a deeper understanding of women's motivations, attitudes and perceptions of preconception care to assist in the development of tailored preconception health services.

Keywords: Preconception care, Chronic disease, Women's health services

\footnotetext{
* Correspondence: amie.steel@uts.edu.au

'Office of Research, Endeavour College of Natural Health, Brisbane,

Queensland, Australia

${ }^{2}$ Australian Research Centre in Complementary and Integrative Medicine,

University of Technology Sydney, Ultimo, New South Wales, Australia

Full list of author information is available at the end of the article
} 


\section{Background}

Preconception care is an approach to health promotion and preventive medicine which focuses on interventions that identify and modify biomedical, behavioural and social risks to a woman's health or pregnancy outcome [1]. By its nature, preconception care relates to care before pregnancy, whether it be a first pregnancy or between consecutive pregnancies, and the importance of this component of contemporary health care has been acknowledged by a range of international bodies and organisations representing health professionals and policy makers [2-5].

\section{Impact of preconception health status on outcomes for women and neonates}

Preconception care has received increased attention due to growing evidence that maternal health prior to conception can directly affect the health of the mother and the fetal environment during pregnancy [2]. The majority of research attention over the last 20 years has been directed to the benefits of folic acid supplementation in preventing birth defects [6-10]. The broader field of preconception care research emphasises the impact of the fetal environment on adverse outcomes such as miscarriage [11], stillbirth [12], congenital disorders [13], and macrosomia [14]. Fetal environment has also been found to impact on risk of the development of chronic diseases such as obesity [15], diabetes and cardiovascular disease [16], and cancer [17] through epigenetic and other cellular responses to developmental exposures [18]. Maternal health behaviours which have been clearly identified as important in the context of preconception care include diet [19], smoking [20], alcohol consumption [21] and exposure to communicable diseases [22].

In light of these developments, and the higher prevalence of important risk behaviours in sub-groups including women with lower socio-economic status $[21,23]$ and teenagers [24], attempts have been made to inform women of childbearing age and modify preconception health behaviours through the development of health policy and guidelines alongside the implementation of preconception care programs within the community [25-29].

\section{Importance of preconception care for women with chronic health conditions}

Chronic and non-communicable diseases are the largest cause of death in the world and as such have a wellestablished global epidemiological and economic impact [30]. In addition, the prevalence of the most common chronic diseases is growing, particularly in developing countries, and is projected to continue to increase [30]. This has led to calls for key stakeholders, including public health researchers, to direct more research towards chronic disease and its impact [30]. In line with this, the clinical impact of preconception care for women with chronic health conditions has received focused attention from researchers. Diabetes has received particular attention because the preconception health of women with either type 1 or type 2 diabetes has been found to impact on the risk of congenital malformations, preterm delivery and perinatal mortality of their offspring [31]. Prepregnancy maternal obesity is linked to an increased likelihood of preterm birth and low birth weight [32] as is hypertension [33], depression [34] and autoimmune disease [35]. Whilst some research has reported no adverse effects from non-immune hypothyroidism in the preconception period if appropriately managed through antepartum care [36], untreated thyroid dysfunction is also linked with an increased risk of obstetric and neonatal complications [37]. In contrast, the risk of adverse pregnancy outcomes for women with epilepsy is directly associated with the antiepileptic drugs used as part of treatment [38].

Some commentators and policymakers have attempted to inform the development of preconception programs to improve prenatal health status and reduce the incidence of adverse outcomes in offspring of women with chronic health conditions [39-41]. Preconception programmes and interventions have been developed and implemented for women of childbearing age with chronic health conditions with varying degrees of success [31,42-45]. A recent systematic review and metaanalysis examining the impact of preconception care for preventing and managing chronic disease confirmed the value in preconception interventions [45]. In particular, the review concluded a reduced incidence of congenital malformations for preconception care of women with diabetes as well as highlighting the importance of preconception management of epilepsy [45].

Effective intervention programmes requires not only knowledge of the effectiveness of the intervention but also insights into the knowledge, attitudes, and health behaviours of the target populations. It is also important that those responsible for preconception programmes and interventions have an understanding of the characteristics which influence women's likelihood to engage with preconception services or undertake health preconception practices. Insights beyond effectiveness outcomes such as these have the capacity to enhance preconception service delivery by ensuring it is tailored and responsive to the needs of the community. In answer, this paper provides a review of international contemporary literature with a specific focus upon the prevalence and nature of use of preconception care practices and services by women with chronic health conditions. By focusing on these factors this review offers an important supplement to efficacy and effectiveness research and will be able to inform future 
preconception care researchers as well as clinicians and policy makers.

\section{Methods}

\section{Search methods}

A database search was conducted to identify peerreviewed literature published between 2003 and October 2014 examining the use of preconception care practices and services by women with a chronic health condition. Literature published before 2003 were not included as previous research examining women's attitudes and knowledge towards preconception care has identified rapid changes to the women's understanding of preconception care over time [46]. Based upon this, manuscripts more than 10 years old would hold limited value to future work. The search was conducted in November 2014 and included PubMed, CINAHL, AMED, and Maternity and Infant Care. The search terms included: preconception care or prenatal care; thyroid diseases; diabetes mellitus; cardiovascular diseases; depressive disorder; obesity; allergy; immunology; and chronic disease. Manual searching of the reference lists of identified papers was also conducted to ensure no relevant papers had been overlooked. Papers were included if they were written in English, presented original research, and reported on the prevalence or nature of use of preconception care. Manuscripts were excluded if they presented results from experimental research designs, or only reported on the impact of preconception care on pregnancy or birth outcomes.

\section{Search outcome}

The search results $(n=672)$ were imported into Endnote referencing and bibliography management software. A total of 93 papers were excluded as duplicates and an additional 556 papers were identified as not complying with the inclusion criteria based upon their title or abstract. Upon reviewing the full text articles, 5 articles were excluded due to their focus on the general population rather than women with a chronic health condition and 4 other papers were excluded as they reported an experimental design. The process undertaken for this review is presented in Figure 1.

\section{Analysis of included papers \\ Critical appraisal and analysis}

The critical appraisal of study quality for research examining clinical outcomes was conducted by applying a quality scoring system, modified from a system previously developed and applied $[47,48]$. This system was designed to systematically compare and evaluate the studies reviewed and allow for appraisal across three dimensions: methodology; reporting of participants' characteristics; and preconception care services examined.
Methodology was appraised according to the use of a representative sampling strategy, adequate sample size, a response or participation rate of $>75 \%$, and low retrospective measurement error (defined as prospective data collection or retrospective data collection within the previous 12 months) [47]. Quantitative papers were appraised according to a determination of sample size based upon a power analysis of $>80 \%$. Where the power analysis was not reported a sample of $>385$ was accepted based upon standard precision analysis principles to account for possible sampling error [49]. Qualitative papers were appraised according to whether they reported achieving thematic saturation during data collection [50]. Appraisal of sample size for qualitative studies was based upon a minimum sample of 15 participants where thematic saturation was not reported. Finally, the studies were assessed for the examination of preconception care services. Studies were critiqued based upon their examination of comprehensive preconception clinical care services - here defined as services where multiple components of preconception care are delivered [51] - rather than uptake of a stand-alone health behaviour, as well as preconception care-related health promotion and patient education. The three dimensions which form the quality assessment tool were selected for inclusion in the critical framework in line with the aim of this review. Each component of the three dimensions was awarded 1 point if the paper achieved the minimum defined requirement and cumulative scores for each paper were calculated with a maximum potential score of 11 . Scores for the studies were assigned independently by two authors. The results were then compared and differences resolved by discussion. A study receiving a quality score of $>8$ was determined to be of acceptable quality as it reflects significant representation across at least 2 of the 3 domains of interest: methodology, reporting of participant characteristics, and preconception services examined.

Categorical grouping of the identified papers was also undertaken by the first author through an inductive process grounded in the content of the papers. This iterative process involved reading and re-reading the papers, extracting relevant information, and identifying common themes within the reported findings. Upon developing the categories, the included studies were examined again and assigned to a relevant category. Individual studies were assigned to as many categories as appropriate based upon the content of the paper.

\section{Results}

An overview of all papers included in the review including preliminary categorical analysis is outlined in Table 1. The review papers identified 14 studies conducted in North America [52-57], the United Kingdom [58-61], Australia [62,63], France [64], and Malta [65]. The studies 


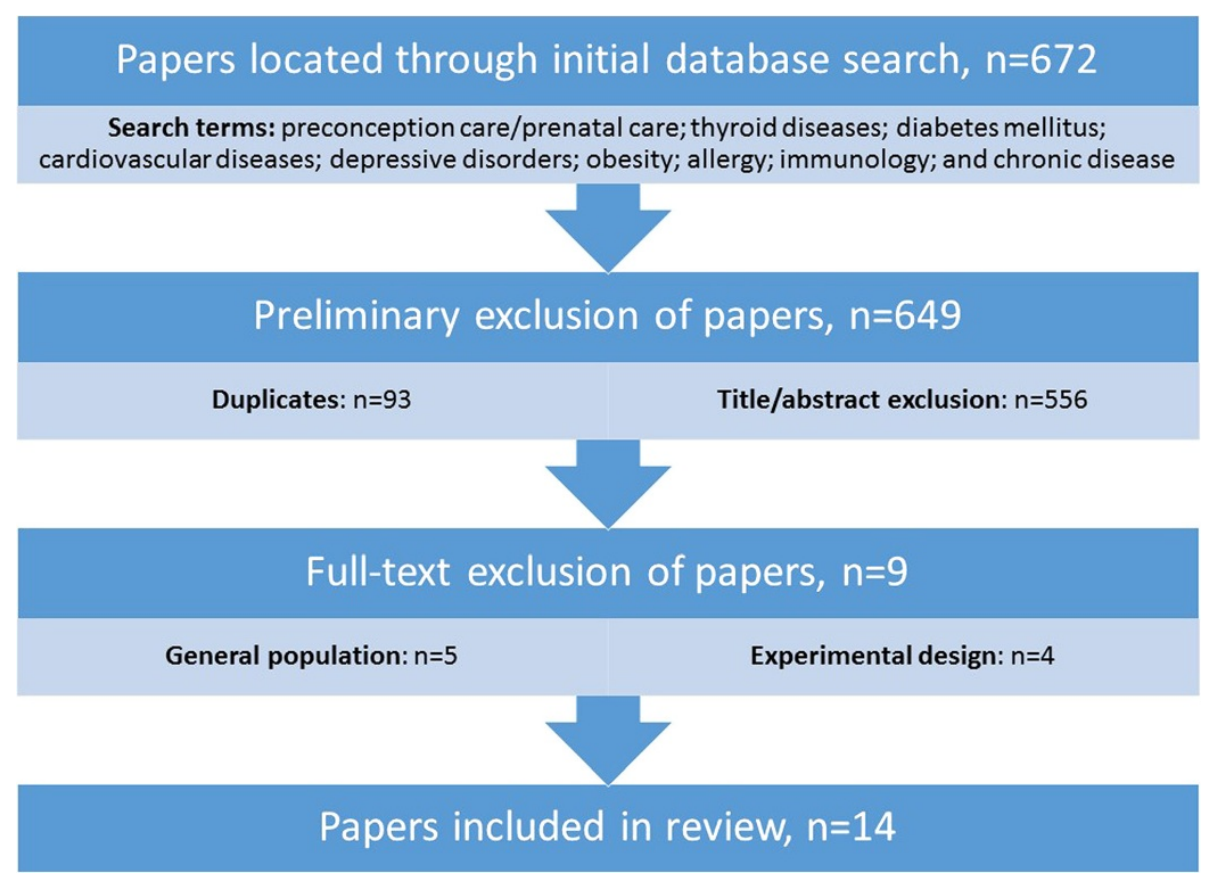

Figure 1 The literature search and selection process (figure uploaded separately).

were published between 2005 and 2014 with the majority [53,56-61,63,65,66] published since 2010. The research designs varied between the studies with both quantitative [52,55-57,61,63-65] and qualitative [53,54,58-60,62] methodologies reported. The quantitative studies utilised a number of survey design approaches and drew on sample sizes between 27 [65] and 6385 [52]. The qualitative studies employed primarily semi-structured interviews involving between 7 [62] and 29 [60] women, although one study used focus groups conducted with a total of 72 women [53]. All of the identified papers examined women with type 1 diabetes [52-66], however women with type 2 diabetes [52,53,56-58,60,61,63], hypertension [53,57] and overweight/obesity $[52,53]$ were also explored in some studies.

The quality score of each relevant individual study is reported in Table 2 . The quality appraisal of included papers identified only 4 papers with a score of $8[52,53,55,61]$. Many studies did not report sufficient detail on the response or participation rate [52-54,56-65] and the majority did not report the time since participant's diagnosis of the chronic health condition [52-54,57,61-63,65] but beyond this the quality issues were inconsistent across studies. Only two studies did not address any of the criteria for methodological quality $[62,64]$.

Through analysis of the findings reported in each of the identified studies, three descriptive categories of results was developed: prevalence of preconception care practices, use of preconception services and characteristics of users; knowledge of the value and impact of preconception care and availability of preconception services; and attitudes, approaches and experiences of preconception care and preconception services.

\section{Prevalence of preconception care practices, use of preconception services, and characteristics of users}

Prevalence of engagement with preconception care services and practices, and the characteristics of women who undertook to use preconception care was examined in 5 of the reviewed papers $[52,55,56,61,63]$. The prevalence estimates ranged between $18.1 \%$ through to $45 \%$ depending upon the health condition being examined $[52,56,61,63]$. Primarily, the studies reporting the prevalence of preconception care use explored the engagement with preconception care counselling services provided through community health clinics with a specific focus on women with type 1 or type 2 diabetes $[56,61,63]$. One large US population study $(n=6385)$ examined folic acid supplementation for women who had diagnosed diabetes or were classified as overweight or obese and found 35\% of total respondents self-administered folic acid [52]. A Canadian study of women attending a health clinic $(\mathrm{n}=464)$ found a notable difference in preconception care service use between women with type 1 (43.1\%) and type $2(18.4 \%)$ diabetes [56], a trend which was also reported in a similar UK study $(n=588)$ [61]. Within the subgroup of women with type 1 diabetes, those who: are younger; have lower weight; have 
Table 1 Summary of identified papers examining preconception care in women with chronic health conditions with thematic categorical groupings

\begin{tabular}{|c|c|c|c|c|c|c|c|c|c|}
\hline \multirow[t]{2}{*}{ Author (Year) } & \multirow[t]{2}{*}{ Country } & \multirow[t]{2}{*}{ Method } & \multirow[t]{2}{*}{ Data source/Participant recruitment } & \multirow[t]{2}{*}{ Target population } & \multirow[t]{2}{*}{ Conditions examined } & \multirow[t]{2}{*}{ Sample } & \multicolumn{3}{|c|}{ Theme } \\
\hline & & & & & & & 1 & II & III \\
\hline Case et al. [52] & United States & Cross-sectional survey & $\begin{array}{l}\text { Texas 1999-2003 Behavioural Risk Factor } \\
\text { Surveillance System }\end{array}$ & Non-pregnant women & $\begin{array}{l}\text { Obesity, overweight, } \\
\text { diabetes }\end{array}$ & 6385 & $x$ & & \\
\hline Chuang et al. [53] & United States & Focus groups & Community and outpatient clinic & Non-pregnant women & $\begin{array}{l}\text { Diabetes, hypertension, } \\
\text { obesity }\end{array}$ & 72 & & $x$ & \\
\hline $\begin{array}{l}\text { Diabetes and Pregnancy } \\
\text { Group [64] }\end{array}$ & France & Cross-sectional survey & $\begin{array}{l}\text { Patients (outpatients and hospitalised) } \\
\text { from specialist diabetes centres }(n=11)\end{array}$ & Non-pregnant women & Type 1 diabetes & 138 & & $x$ & \\
\hline Griffiths et al. [54] & United Kingdom & Semi-structured interviews & $\begin{array}{l}\text { UK specialist diabetes antenatal clinics } \\
(n=4)\end{array}$ & Pregnant women & Type 1 diabetes & 15 & & $x$ & $x$ \\
\hline Kallas-Koeman et al. [56] & Canada & $\begin{array}{l}\text { Prospective observation } \\
\text { and survey }\end{array}$ & $\begin{array}{l}\text { Electronic medical records from diabetes } \\
\text { clinic }\end{array}$ & Non-pregnant women & $\begin{array}{l}\text { Type } 1 \text { and Type } 2 \\
\text { diabetes }\end{array}$ & 464 & $x$ & & \\
\hline Kim et al. [55] & United States & Prospective survey & $\begin{array}{l}\text { Translating Research into Action for } \\
\text { Diabetes (TRIAD) cohort study }\end{array}$ & Non-pregnant women & Type 1 diabetes & 302 & $x$ & & \\
\hline King and Wellard [62] & Australia & $\begin{array}{l}\text { Collective case study } \\
\text { (via in-depth interviews) }\end{array}$ & $\begin{array}{l}\text { Local diabetes services and youth } \\
\text { diabetes website }\end{array}$ & $\begin{array}{l}\text { Women with previous } \\
\text { pregnancy }\end{array}$ & Type 1 diabetes & 7 & & & $x$ \\
\hline Lavender et al. [58] & England & $\begin{array}{l}\text { Semi-structured interviews } \\
\text { and focus groups }\end{array}$ & $\begin{array}{l}\text { Obstetric and diabetes clinics in hospitals } \\
\text { in North-West England }(n=3)\end{array}$ & $\begin{array}{l}\text { Women with previous } \\
\text { pregnancy }\end{array}$ & $\begin{array}{l}\text { Type } 1 \text { and Type } 2 \\
\text { diabetes }\end{array}$ & 22 & & & $x$ \\
\hline McCorry et al. [59] & Ireland & Semi-structured interviews & & Non-pregnant women & Type 1 diabetes & 14 & & & $x$ \\
\hline Mittal et al. [57] & United States & Cross-sectional survey & $\begin{array}{l}\text { San Francisco General Hospital Family } \\
\text { Health Center registry }\end{array}$ & Non-pregnant women & $\begin{array}{l}\text { Diabetes, hypertension, } \\
\text { obesity }\end{array}$ & 27 & & $x$ & $x$ \\
\hline Murphy et al. [60] & England & Semi-structured interviews & $\begin{array}{l}\text { Diabetes specialist antenatal clinics } \\
(n=3)\end{array}$ & $\begin{array}{l}\text { Women who did not attend } \\
\text { preconception care }\end{array}$ & $\begin{array}{l}\text { Type } 1 \text { or Type } 2 \\
\text { diabetes }\end{array}$ & 29 & & & $x$ \\
\hline Sapiano et al. [65] & Malta & Longitudinal survey & Diabetes hospital outpatient clinic & Non-pregnant women & Type 1 diabetes & 27 & & $x$ & \\
\hline Tripathi et al. [61] & England & Cross-sectional survey & Northern Diabetes in Pregnancy Survey & $\begin{array}{l}\text { Women with previous } \\
\text { pregnancy }\end{array}$ & $\begin{array}{l}\text { Type } 1 \text { or Type } 2 \\
\text { diabetes }\end{array}$ & 588 & $x$ & & \\
\hline Zhu et al. [63] & Australia & Prospective survey & Diabetes hospital outpatient clinic & Non-pregnant women & $\begin{array}{l}\text { Type } 1 \text { or Type } 2 \\
\text { diabetes }\end{array}$ & 51 & $x$ & $x$ & \\
\hline
\end{tabular}

I: Prevalence of engagement with preconception services and characteristics of users.

II: Women's knowledge of preconception care benefits, preconception information sources, and availability of preconception services.

III: Women's attitudes and experiences of preconception care and preconception services. 
Table 2 Quality assessment of manuscripts identified through the literature review process BIBU

\begin{tabular}{|c|c|c|c|c|c|c|c|c|c|c|c|c|c|c|c|}
\hline & $\begin{array}{l}\text { Dimensions } \\
\text { for quality } \\
\text { assessment }\end{array}$ & $\begin{array}{l}\text { Lavender } \\
\text { et al. [58] }\end{array}$ & $\begin{array}{l}\text { Case } \\
\text { et al. [52] }\end{array}$ & $\begin{array}{l}\text { Murphy } \\
\text { et al. [60] }\end{array}$ & $\begin{array}{l}\text { Diabetes \& } \\
\text { Pregnancy } \\
\text { Group [64] }\end{array}$ & $\begin{array}{l}\text { McCorry } \\
\text { et al. [59] }\end{array}$ & $\begin{array}{l}\text { Tripathi } \\
\text { et al. [61] }\end{array}$ & $\begin{array}{l}\text { Zhu } \\
\text { et al. [63] }\end{array}$ & $\begin{array}{l}\text { Mittal } \\
\text { et al. [57] }\end{array}$ & $\begin{array}{l}\text { Chuang } \\
\text { et al. [53] }\end{array}$ & $\begin{array}{l}\text { Kallas- } \\
\text { Koeman } \\
\text { et al. [56] }\end{array}$ & $\begin{array}{l}\text { Kim } \\
\text { et al. [55] }\end{array}$ & $\begin{array}{l}\text { Sapiano } \\
\text { et al. [65] }\end{array}$ & $\begin{array}{l}\text { Griffiths } \\
\text { et al. [54] }\end{array}$ & $\begin{array}{l}\text { King and } \\
\text { Wellard [62] }\end{array}$ \\
\hline \multirow[t]{4}{*}{ Methodology } & $\begin{array}{l}\text { Representative } \\
\text { sampling strategy }\end{array}$ & & $x$ & & & & $x$ & & $x$ & & & $x$ & & & \\
\hline & Sample size ${ }^{\neq}$ & $x$ & $x$ & $x$ & & & $x$ & & & $x$ & $x$ & & & $x$ & \\
\hline & $\begin{array}{l}\text { Response/ } \\
\text { participation } \\
\text { rate }>75 \%\end{array}$ & & & & & & $x$ & & & & & $x$ & & & \\
\hline & $\begin{array}{l}\text { Low retrospective } \\
\text { measurement bias }\end{array}$ & & $x$ & & & $x$ & $x$ & $x$ & & $x$ & $x$ & & $x$ & $x$ & \\
\hline \multirow{5}{*}{$\begin{array}{l}\text { Reporting of } \\
\text { participant } \\
\text { characteristics }\end{array}$} & Pregnancy status & $x$ & $x$ & $x$ & $x$ & $x$ & $x$ & $x$ & $x$ & $x$ & $x$ & & & $x$ & \\
\hline & Age & $x$ & $x$ & $x$ & $x$ & $x$ & $x$ & $x$ & $x$ & $x$ & $x$ & $x$ & $x$ & $x$ & $x$ \\
\hline & Ethnicity & $x$ & $x$ & $x$ & & & $x$ & & $x$ & $x$ & & $x$ & & & \\
\hline & $\begin{array}{l}\text { Indicator of } \\
\text { socioeconomic } \\
\text { status }\end{array}$ & & $x$ & & $x$ & & & $x$ & & $x$ & & $x$ & & & \\
\hline & $\begin{array}{l}\text { Duration of chronic } \\
\text { health condition }\end{array}$ & $x$ & & $x$ & $x$ & $x$ & & & & & $x$ & $x$ & & & \\
\hline \multirow{2}{*}{$\begin{array}{l}\text { Preconception } \\
\text { services } \\
\text { examined }\end{array}$} & $\begin{array}{l}\text { Preconception } \\
\text { clinical care delivery }\end{array}$ & $x$ & & $x$ & $x$ & $x$ & $x$ & $x$ & & $x$ & $x$ & $x$ & $x$ & $x$ & $x$ \\
\hline & $\begin{array}{l}\text { Health promotion } \\
\text { and patient } \\
\text { education }\end{array}$ & $x$ & $x$ & $x$ & $x$ & $x$ & & & $x$ & $x$ & & $x$ & $x$ & $x$ & $x$ \\
\hline \multicolumn{2}{|c|}{ Total quality score } & 7 & 8 & 7 & 6 & 6 & 8 & 5 & 5 & 8 & 6 & 8 & 4 & 6 & 3 \\
\hline
\end{tabular}

${ }^{\text {F}}$ Sample size defined in quantitative studies as $>500$ or with a determined statistical power of $>80 \%$ and in qualitative studies as $>15$ or reported thematic saturation. 
longer duration of diabetes; and only use insulin for treatment, are more likely to report preconception care practices such as focusing on glucose control or family planning counselling [55].

\section{Women's knowledge of preconception care benefits, preconception information sources and availability of services}

This category overviews the findings from the included studies as it relates specifically to participants knowledge of the benefits of appropriate preconception care behaviours such as avoiding tobacco and alcohol use, undertaking regular exercise, or supplementing with folate. Women's awareness of available preconception services and sources of information regarding preconception health are also included in this category. The examination of women's knowledge of preconception care and availability of preconception services for women with a chronic health condition has been disparate and individual studies have explored the topic from different angles. However, significant gaps in women's knowledge have been consistently identified across the six studies [53,54,57,63-65] examining this topic. Such gaps include a limited knowledge of the pregnancy risks associated with chronic medical conditions whether as a general risk $[53,57,65]$, or associated with specific adverse outcomes [64]. A study involving focus groups of non-pregnant women with diabetes, hypertension or obesity also found that participants' knowledge of behaviours which optimise preconception health and the impact of chronic health conditions on contraceptive choices was limited [53]. More than half (60\%) of women who attended a hospital for antenatal services with diabetes were found to have no knowledge of the availability of a preconception service at the hospital.

A cross-sectional survey $(n=138)$ of women with type 1 diabetes investigating the factors that influence the women's level of knowledge regarding pregnancy risk and preconception care found participants were better informed if they had a younger age of onset of the health condition, were multiparous, had a higher level of education, or monitored their blood glucose more than three times each day [64]. Sources of information related to pregnancy risk and preconception care needs for women with a chronic health condition were also explored. The majority of women (85\%) had received information about pregnancy from a health professional or through leaflets, although $14 \%$ had received notification after a previous unplanned pregnancy and therefore were unable to engage with preconception services for that pregnancy [64]. This finding was also confirmed through a study drawing on semi-structured interviews of pregnant women with type 1 diabetes who sought advice from their usual health professional early in pregnancy with information only occasionally provided to them preconception [54]. Another smaller survey of women with type 1 diabetes $(n=27)$ complements the findings of the larger study but reported preferred rather than actual information sources. This smaller study indicated women with type 1 diabetes preferred their doctor or specialist as a source of information (81\%) followed by books or leaflets $(51 \%)$ the internet (46\%) and diabetes clinic staff (46\%). Standard media was the least preferred (30\%) [65].

\section{Women's attitudes and experiences of preconception care and preconception services}

This category specifically relates to women's attitudes towards the concept of using preconception services or the experiences of those who have used preconception services in the past and includes 6 identified studies [54,57-60,62]. Women reported experiencing emotional stress whilst attempting to comply with preconception requirements unique to their diagnosed health condition and avoid pregnancy complications $[58,59,62,63]$, and needing discipline to follow the guidelines outlined by health professionals to minimise their pregnancy risk [62]. Others reported that women's experience of preconception counselling contributed to fear of pregnancy complications to such a level that it made the decision to conceive more difficult [54]. Within the studies exploring women's attitude and experience of preconception care, a trend towards fear and resistance to the present approach to preconception counselling including a perceived medicalisation of the condition $[54,58,59]$ and a preference for more holism in the approach to preconception care [59] is evident.

Aside from these concerns, the decision to conceive is reportedly associated with a change in health behaviour, even for those women who were not always strict with their diet and lifestyle [62] which has been attributed to a desire to be as healthy as possible to ensure the best outcomes for the baby. However, this change is not always able to be maintained by the woman and can result in a haphazard approach to preconception care [58]. Barriers to women's ability to engage with, or maintain, preconception practices not only include the emotional concerns highlighted above, but also employment type, particularly as they relate to the ability to implement and maintain diet and lifestyle change [62]. In addition, women have also identified the need to share private information, regarding their intentions to conceive, with employers to enable flexibility for medical appointments during work hours [58] and the perceived time needed for attending appointments [63]. This impact of time for appointments may also be exacerbated for those living in rural areas by the geographical distance to preconception service providers [63]. 


\section{Discussion}

This review provides an examination of the prevalence and nature of the use of preconception care services by women with chronic health conditions worldwide. The significance of this work is underpinned by the international commitment to both preconception care and the management of chronic health in a population health context. Clear policy statements describing the significance and consequence of preconception care have been developed by international organisations and governing bodies [2-5]. A key element in these policies has been the importance of attenuating the severity of chronic health conditions prior to pregnancy to minimise the risk of obstetric and postnatal health problems. In line with this, a growing trend of research examining the use of preconception care practices by women with chronic health conditions is highlighted by this review, with 10 out of 14 studies published since 2010. As is common with the emerging nature of this research topic, there is inconsistency in some of the work conducted and limited scope in other areas. There are a number of gaps in available knowledge to inform those committed to translating the current policies and guidelines into meaningful and effective preconception programmes and services. One such gap is due to a limited approach to data collection and analysis which does not give adequate consideration to the needs of women with differing chronic health conditions, or the breadth and diversity of chronic health conditions which may benefit from preconception health services. Similarly, the scope of health behaviours and health services used by women with chronic health conditions for preconception care has been relatively narrow. Another knowledge gap in this field is due to a focus on retrospective cross-sectional studies with little examination of women's change in use of health services prior to attempting to conceive, whilst actively planning conception, and into the antenatal period. Finally, very little of the existing research has examined the motivations, perceptions and attitudes towards preconception care and preferences for preconception services of women with chronic health conditions. Without dedicating future research attention to these areas, the development of preconception services and programs which are sensitive to the health behaviours and needs of the women they are targeting will be limited. As such, a possible agenda for future research to address these gaps, whilst not exhaustive, is proposed. Due to the breadth of research still needed in this field, the following agenda prioritises: sophistication in data analysis; longitudinal studies and improved representativeness; and attention to understanding the motivations, perceptions and attitudes of preconception care stakeholders.

\section{A broad and sophisticated approach to research design and analysis}

There is value in broadening the range of chronic health conditions examined in the context of preconception care beyond the current dominant focus on type 1 diabetes. Given the known health implications of maternal type 2 diabetes [31], obesity [32], hypertension [33], depression [34], autoimmune disease [35] and thyroid disorders [37] for both mother and offspring, these additional conditions also require close attention. In fact, in light of the growing rates of obesity in both developed $[67,68]$ and transitional $[69,70]$ economies and the increasing awareness of the importance of addressing depression in contemporary maternity care [71] it could be argued that these two conditions need a priority focus in future research.

The development of knowledge in this topic area would also benefit from a differential approach to women's conception intentions within research design and analysis. Current research indicates that women who are actively trying to conceive, those trying to avoid pregnancy, and those that are ambivalent differ in a range of characteristics such as age, parity, importance of motherhood, selfidentifying a fertility problem, relationship satisfaction and economic hardship [72]. It may be beneficial to examine these groups of women separately and in contrast to one another given the potential differences in their preferences and needs from a preconception service, their ability to commit to preconception care planning or changes, and the goals which motivate them to make health behaviour changes. By taking this approach, researchers will be better positioned to provide meaningful findings to health professionals and policy makers which can inform the provision of tailored and relevant preconception care for all women of childbearing age with chronic health conditions.

Beyond a specific and discrete focus on women with chronic health conditions, there is also a need to expand the research scope to include other stakeholders such as women's partners and health care providers. Given the impact a woman's partner can have on women's intention to conceive [72], and potentially on their engagement with preconception care [73], examination of the partners of women with a chronic health condition in the context of preconception care may provide valuable insights to assist in the development of policies and programmes. Likewise, the findings identified through this literature review suggest the current approach of health professionals providing preconception care is perceived as more medicalised and less holistic than would be preferred by women engaging with these professionals. Future research needs to more closely examine the interactions between health professionals and women with chronic health conditions undertaking preconception care to clarify this perception 
and assist health professionals in approaching these women in a manner which will encourage confidence and lasting health behaviour change.

A final avenue which would add breadth to our understanding of the preconception care patterns of women with chronic health conditions is the study of practices and behaviours women undertake as part of their preconception care. Current research examining health behaviours during the preconception period focus on smoking [20], alcohol use [21], diet [19] and exposure to communicable disease [22]. This work needs to be expanded to include focus upon general health service use such as visits with primary care practitioners including general practitioners and family physicians, but also specific health service use such as specialist doctors and complementary and alternative medicine (CAM) providers. In fact, given the high rates of CAM use reported for individuals with chronic health conditions $[74,75]$, and the similarly high rates identified in women receiving fertility treatments [76], the use of CAM during the preconception period and for preconception care by women with chronic health conditions would benefit from focused attention.

\section{Improved consideration of temporal changes and sample representativeness}

Current health services research which examines preconception care for women with chronic health conditions, with one exception [52], draws upon samples which are not generalisable due to the small sample sizes $[53,57,58,63,65]$ and non-representative sampling methods [54-56,58-60,62-65]. As such the majority of work in this area has limited external validity. There is a clear need to explore this topic using nationallyrepresentative samples to provide more robust insights into the prevalence of preconception health behaviours and patterns of preconception service use by women with chronic health conditions. A nationally-representative study design will enhance the external validity of any data in relationship to a target population of the country it is intended to represent [77]. In order for this research approach to best contribute to the current knowledge associated with the use of preconception care by women with chronic health conditions, it is important that such data includes a broad range of chronic health conditions reflective of the range of pre-pregnancy conditions linked with adverse birth outcomes, health behaviours, health service utilisation and attitudes towards health and health care. It would be most cost effective where possible to use existing data sources for this analysis (e.g. the Australian Longitudinal Study on Women's Health linked to administrative data from the Medicare Benefits Schedule [78] for additional information on access to services).
Longitudinal data will also be a valuable component of future research as it allows for the examination of changes in behaviour throughout the childbearing years [79]. Drawing upon longitudinal data would enable researchers to explore differences in individual health behaviours, health service use, and attitudes towards health and health care during various life stages including long term preconception, immediate preconception, antenatal, postnatal and interconception periods. The use of longitudinal data would allow for not only comparisons across defined life stages but also changes for individual women over time. Within the context of chronic health conditions this level of analysis would identify the degree to which women with chronic health conditions change their behaviour once planning to conceive and also the degree to which these changes in behaviour continue on through pregnancy.

\section{The contribution of exploring motivations, attitudes and perceptions to understanding preconception practices}

Complementing the above proposed research activities with a comprehensive examination of the motivations, attitudes and perceptions informing preconception health behaviour is vital. It is only through understanding these intrinsic characteristics of women with chronic health conditions that preconception programmes and services can be developed which respond adequately to women's needs. Qualitative research designs are best placed to afford the necessary insights into this important aspect of preconception research. The approach of qualitative methodology is interpretive, pragmatic, grounded in the lived experiences of individuals, and commonly occurs in natural (rather than constructed) settings [80]. Application of research designs incorporating qualitative methods would enable an exploration of women's perceived preferences and needs regarding preconception care service delivery including availability and access. This needs to be considered in the context of the current findings of emotional stress and fear but also the desire for holism within the preconception care services encountered by women with chronic health conditions identified within this review $[54,58,59]$.

The use of qualitative methodology will also enable a closer examination of the motivations which may inform women using or not using preconception services, or modifying health behaviour in the preconception period - particularly for those intending to conceive. Similarly, it would provide an important opportunity to explore the perception and understanding of men regarding their role as male partners during the preconception care process for women with chronic health conditions, and likewise capture the experience and attitude of health professionals. 


\section{Strength and limitations of this review}

This review provides the first synthesis of health service research studies examining preconception care use by women with chronic health conditions. It highlights the limited evidence base currently available to guide policy and practice development. Most importantly it sets out a research agenda to expand the evidence base to enable better models of preconception care to be developed that respond to the needs of women with a range of chronic diseases.

This review has a number of limitations due to the heterogeneity of the studies restricting the ability to comprehensively compare findings across studies or interpret a consistent trend in results. Likewise, the dominance of small sample sizes utilised to provide the data reported in the studies restricts the capacity to infer implications from the findings beyond the study settings being examined. There was an over-representation of studies investigating type 1 diabetes in preference to other chronic health conditions and, as highlighted by one of the identified studies [56], the results from the research of type 1 diabetes may not represent the patterns and experiences of women with other chronic conditions. Similarly, the lack of differentiation between those intending to conceive and those who conceived accidently may confuse the results of the identified studies. Despite these limitations, this review provides the first overview of health services research associated with the topic globally and offers key insights for those providing care to women with chronic health conditions as well as offering a clear direction for the focus of future research on this topic.

\section{Conclusions}

Preconception care for women with chronic health conditions is clearly a topic of increasing interest for researchers and of increasing importance for health care providers and policy makers. The health services research in this field is still emerging and even as the current evidence provides insights into the prevalence and knowledge of preconception care, attitudes towards preconception services and practices, and the characteristics of users for this subset of the population there remain significant research gaps requiring address. A framework for future research requires more sophisticated study design and methodology, the inclusion of more representative study populations, the analysis of longitudinal data, and dedicated attention to the attitudes, motivations and experiences of key stakeholders. By taking this more expansive and focused approach to the examination of preconception care for women with chronic health conditions, future research will be better placed to inform health professionals, health services managers and policy makers in the development of relevant and meaningful preconception care programs and services for women with chronic conditions.

\section{Competing interests}

$J \mathrm{~L}$ is Chief Investigator of an Australia Research Council Linkage Grant which involves case and in-kind support from Family Planning New South Wales and Bayer Australia. There are no other real or potential conflicts of interest to report.

\section{Authors' contributions}

AS and $J \mathrm{~L}$ conceived of the study. AS undertook the literature search, review and categorisation. AS and JA participated in the collection, extraction, analysis and interpretation of the data. AS drafted the manuscript. AS, JL and JA revised the manuscript. All authors read and approved the final manuscript.

\section{Acknowledgements}

There are no additional acknowledgements for this work.

\section{Author details}

'Office of Research, Endeavour College of Natural Health, Brisbane, Queensland, Australia. ${ }^{2}$ Australian Research Centre in Complementary and Integrative Medicine, University of Technology Sydney, Ultimo, New South Wales, Australia. ${ }^{3}$ Australian Research Centre in Sex, Health and Society, Faculty of Health Sciences, La Trobe University, Melbourne, Victoria, Australia. ${ }^{4} U Q$ Centre for Clinical Research, The University of Queensland, Brisbane, Queensland, Australia.

Received: 12 September 2014 Accepted: 20 January 2015

Published online: 18 February 2015

\section{References}

1. Posner SF, Johnson K, Parker C, Atrash H, Biermann J. The national summit on preconception care: a summary of concepts and recommendations. Matern Child Health J. 2006:10(1):199-207.

2. Committee on gynecologic practice: the importance of preconception care in the continuum of women's health care. In: ACOG Committee Opinion. http://www.acog.org/Resources-And-Publications/Committee-Opinions/ Committee-on-Gynecologic-Practice/The-Importance-of-Preconception-Carein-the-Continuum-of-Womens-Health-Care; 2005.

3. Christiansen C, Chandra-Mouli V, Ogbaselassie L, Willumsen J, Mason E. Meeting to develop a global consensus on preconception care to reduce maternal and childhood mortality and morbidity. Geneva: World Health Organization; 2012

4. Johnson K, Posner SF, Biermann J, Cordero JF, Atrash H. Recommendations to improve preconception health and health care - United States. Morb Mortal Wkly Rep. 2006;55(RR06):1-23.

5. Preconception Care [http://www.nice.org.uk/quidance/qs6/chapter/qualitystatement-7-preconception-care]

6. Wilson R, Davies $G$, Desilets $V$, Reid G, Summers A, Wyatt $P$, et al. The use of folic acid for the prevention of neural tube defects and other congenital anomalies. J Obstet Gynaecol Can. 2003;25(11):959-73.

7. Berry RJ, Li Z, Erickson JD, Li S, Moore CA, Wang H, et al. Prevention of neural-tube defects with folic acid in China. N Engl J Med. 1999:341(20):1485-90.

8. Boyles A, Ballard J, Gorman E, McConnaughey D, Cabrera R, Wilcox A, et al. Association between inhibited binding of folic acid to folate receptor $a$ in maternal serum and folate-related birth defects in Norway. Hum Reprod. 2011;26(8):2232-8

9. Yi Y, Lindemann M, Colligs A, Snowball C. Economic burden of neural tube defects and impact of prevention with folic acid: a literature review. Eur J Pediatr. 2011;170(11):1391-400.

10. Khodr ZG, Lupo PJ, Agopian A, Canfield MA, Case AP, Carmichael SL, et al. Preconceptional folic acid-containing supplement use in the national birth defects prevention study. Birth Defects Res A Clin Mol Teratol. 2014;100(6):472-82

11. Nielsen A, Gerd Hannibal C, Eriksen Lindekilde B, Tolstrup J, Frederiksen K, Munk $C_{\text {, }}$ et al. Maternal smoking predicts the risk of spontaneous abortion. Acta Obstet Gynecol Scand. 2006;85(9):1057-65.

12. Signorello LB, Mulvihill JJ, Green DM, Munro HM, Stovall M, Weathers $R E$, et al. Stillbirth and neonatal death in relation to radiation exposure before conception: a retrospective cohort study. Lancet. 2010;376(9741):624-30. 
13. Shannon GD, Alberg C, Nacul L, Pashayan N. Preconception health care and congenital disorders: mathematical modelling of the impact of a preconception care programme on congenital disorders. Br J Obstet Gynaecol. 2013;120(5):555-67.

14. Strutz KL, Richardson $\sqcup$, Hussey JM. Preconception Health Trajectories and Birth Weight in a National Prospective Cohort. J Adolescent Health. 2012;51(6):629-36.

15. Ehrenthal DB, Maiden K, Rao A, West DW, Gidding SS, Bartoshesky L, et al. Independent relation of maternal prenatal factors to early childhood obesity in the offspring. Obstet Gynecol. 2013;121(1):115-121.

16. Le Clair C, Abbi T, Sandhu H, Tappia PS. Impact of maternal undernutrition on diabetes and cardiovascular disease risk in adult offspring. Can J Physio Pharmacol. 2009;87(3):161-79.

17. Miligi L, Benvenuti A, Mattioli S, Salvan A, Tozzi GA, Ranucci A, et al. Risk of childhood leukaemia and non-Hodgkin's lymphoma after parental occupational exposure to solvents and other agents: the SETIL Study. Occup Environ Med. 2013;70(9):648-55.

18. Wang G, Walker SO, Hong X, Bartell TR, Wang X. Epigenetics and Early Life Origins of Chronic Noncommunicable Diseases. J Adolesc Health. 2013;52(2, Supplement 2):S14-21.

19. Kind KL, Moore VM, Davies MJ. Diet around conception and during pregnancy - effects on fetal and neonatal outcomes. Reprod Biomed Online. 2006;12(5):532-41.

20. Flenady V, Middleton P, Smith GC, Duke W, Erwich JJ, Khong TY, et al. Stillbirths: the way forward in high-income countries. Lancet. 2011;377(9778):1703-17.

21. Anderson J, Ebrahim S, Floyd L, Atrash H. Prevalence of Risk Factors for Adverse Pregnancy Outcomes During Pregnancy and the Preconception Period-United States, 2002-2004. Matern Child Health J. 2006;10(1):101-6.

22. Goldenberg RL, Thompson C. The infectious origins of stillbirth. Am J Obstet Gynecol. 2003;189(3):861-73.

23. Bombard JM, Dietz PM, Galavotti C, England LJ, Tong VT, Hayes DK, et al. Chronic diseases and related risk factors among low-income mothers. Matern Child Health J. 2012;16(1):60-71.

24. Heavey E. Don't miss preconception care opportunities for adolescents. MCN Am J Matern Child Nurs. 2010;35(4):213-9.

25. Farrell-Carnahan L, Hettema J, Jackson J, Kamalanathan S, Ritterband LM, Ingersoll KS. Feasibility and promise of a remote-delivered preconception motivational interviewing intervention to reduce risk for alcohol-exposed pregnancy. Telemed J E Health. 2013;19(8):597-604

26. Fischl AFR, Herman WH, Sereika SM, Hannan M, Becker D, Mansfield MJ, et al. Impact of a preconception counseling program for teens with type 1 diabetes (READY-Girls) on patient-provider interaction, resource utilization, and cost. Diabetes Care. 2010;33(4):701-5.

27. Dunlop AL, Logue KM, Thorne C, Badal HJ. Change in Women's Knowledge of General and Personal Preconception Health Risks Following Targeted Brief Counseling in Publicly Funded Primary Care Settings. Am J Health Promot. 2013;27(sp3):S50-7.

28. Tieu J, Middleton P, Crowther CA. Preconception care for diabetic women for improving maternal and infant health. Cochrane Collect. 2010;12(12):CD007776. doi:10.1002/14651858.CD007776.pub2.

29. Dunlop AL, Dretler AW, Badal HJ, Logue KM. Acceptability and Potential Impact of Brief Preconception Health Risk Assessment and Counseling in the WIC Setting. Am J Health Promot. 2013;27(sp3):S58-65.

30. Yach D, Hawkes C, Gould CL, Hofman KJ. The Global Burden of Chronic Diseases: overcoming impediments to prevention and control. J Am Med Assoc. 2004;291:2616-22.

31. Wahabi HA, Alzeidan RA, Bawazeer GA, Alansari LA, Esmaeil SA. Preconception care for diabetic women for improving maternal and fetal outcomes: a systematic review and meta-analysis. BMC Pregnancy Childbirth. 2010;10(1):63

32. McDonald SD, Han Z, Mulla S, Beyene J. Overweight and obesity in mothers and risk of preterm birth and low birth weight infants: systematic review and meta-analyses. Br Med J. 2010;341:c3428.

33. Harville EW, Viikari JS, Raitakari OT. Preconception cardiovascular risk factors and pregnancy outcome. Epidemiol. 2011;22(5):724.

34. Phillips GS, Wise LA, Rich-Edwards JW, Stampfer MJ, Rosenberg L. Prepregnancy Depressive Symptoms and Preterm Birth in the Black Women's Health Study. Ann Epidemiol. 2010;20(1):8-15.

35. Canti V, Castiglioni MT, Rosa S, Franchini S, Sabbadini MG, Manfredi AA, et al. Pregnancy outcomes in patients with systemic autoimmunity. Autoimmunity. 2012;45(2):169-75
36. Khan I, Witczak J, Hadjieconomou S, Okosieme O. Preconception thyroidstimulating hormone and Pregnancy outcomes in Women with Hypothyroidism. Endocr Pract. 2013;19(4):659-62

37. van den Boogaard E, Vissenberg R, Land JA, van Wely M, van der Post JAM Goddijn $M$, et al. Significance of (sub)clinical thyroid dysfunction and thyroid autoimmunity before conception and in early pregnancy: a systematic review. Hum Reprod Update. 2011;17(5):605-19.

38. Meador K, Reynolds MW, Crean S, Fahrbach K, Probst C. Pregnancy outcomes in women with epilepsy: a systematic review and meta-analysis of published pregnancy registries and cohorts. Epilepsy Res. 2008:81(1):1-13.

39. Lateef A, Petri M. Management of pregnancy in systemic lupus erythematosus. Nat Rev Rheumatol. 2012;8(12):710-8.

40. Mahmud M, Mazza D. Preconception care of women with diabetes: a review of current guideline recommendations. BMC Women Health. 2010;10(1):5

41. Lowe SA, Brown MA, Dekker GA, Gatt S, McLintock CK, McMahon LP, et al Guidelines for the management of hypertensive disorders of pregnancy 2008. Aust N Z J Obstet Gynaecol. 2009;49(3):242-6.

42. Oostdam N, van Poppel MN, Wouters MG, van Mechelen W. Interventions for preventing gestational diabetes mellitus: a systematic review and meta-analysis. J Women Health. 2011;20(10):1551-63.

43. Dean SV, Imam AM, Lassi ZS, Zulfiqar AB. Systematic Review of Preconception Risks and Interventions. Pakistan: Division of Women and Child Health, Aga Khan University; 2013.

44. Temel S, van Voorst SF, Jack BW, Denktaş S, Steegers EA. Evidence-based preconceptional lifestyle interventions. Epidemiol Rev. 2014;36(1):19-30.

45. Lassi Z, Imam A, Dean S, Bhutta Z. Preconception care: screening and management of chronic disease and promoting psychological health. Reprod Health. 2014;11 Suppl 3:S5.

46. Ahluwalia IB, Daniel KL. Are women with recent live births aware of the benefits of folic acid. MMWR Recomm Rep. 2001;50:3-14.

47. Adams J, Barbery G, Lui C-W. Complementary and Alternative Medicine Use for Headache and Migraine: A Critical Review of the Literature. Headache: J Head Face Pain. 2012;53(3):459-73.

48. Steel A, Frawley J, Adams J, Diezel H. Trained or professional doulas in the support and care of pregnant and birthing women: a critical integrative review. Health Social Care Community 2014. doi:10.1111/hsc.12112.

49. Chow S-C, Shao J, Wang H. Sample size calculations in clinical research, vol. 20, 2nd edn. Florida: Chapman \& Hall; 2008.

50. Creswell JW, Plano Clark VL. Designing and Conducting Mixed Methods Research. 2nd ed. Thousand Oaks: Sage; 2011.

51. Johnson K, Posner SF, Biermann J, Cordero JF, Atrash HK, Parker CS, et al. Recommendations to improve preconception health and health care-United States. Morb Mortal Wkly Rep. 2006;55(4):1-23.

52. Case AP, Ramadhani TA, Canfield MA, Beverly L, Wood R. Folic acid supplementation among diabetic, overweight, or obese women of childbearing age. J Obstet Gynecol Neonatal Nurs. 2007;36(4):335-41.

53. Chuang $\mathrm{CH}$, Velott DL, Weisman CS. Exploring knowledge and attitudes related to pregnancy and preconception health in women with chronic medical conditions. Matern Child Health J. 2010;14(5):713-9.

54. Griffiths F, Lowe P, Boardman F, Ayre C, Gadsby R. Becoming pregnant exploring the perspectives of women living with diabetes. Br J Gen Pract. 2008;58(548):184-90.

55. Kim C, Ferrara A, McEwen LN, Marrero DG, Gerzoff RB, Herman WH, et al. Preconception care in managed care: the translating research into action for diabetes study. Am J Obstet Gynecol. 2005;192(1):227-32.

56. Kallas-Koeman M, Khandwala F, Donovan LE. Rate of preconception care in women with type 2 diabetes still lags behind that of women with type 1 diabetes. Can J Diabetes. 2012;36(4):170-4

57. Mittal P, Dandekar A, Hessler D. Use of a Modified Reproductive Life Plan to Improve Awareness of Preconception Health in Women with Chronic Disease. Perm J. 2014;18(2):28

58. Lavender T, Platt MJ, Tsekiri E, Casson I, Byrom S, Baker L, et al. Women's perceptions of being pregnant and having pregestational diabetes. Midwifery. 2010;26(6):589-95.

59. McCorry NK, Hughes C, Spence D, Holmes VA, Harper R. Pregnancy Planning and Diabetes: A Qualitative Exploration of Women's Attitudes Toward Preconception Care. J Midwifery Women Health. 2012;57(4):396-402.

60. Murphy HR, Temple RC, Ball VE, Roland JM, Steel S, Zill EHR, et al. Personal experiences of women with diabetes who do not attend pre-pregnancy care. Diabet Med. 2010;27(1):92-100 
61. Tripathi A, Rankin J, Aarvold J, Chandler C, Bell R. Preconception counseling in women with diabetes: a population-based study in the north of England. Diabetes Care. 2010;33(3):586-8.

62. King R, Wellard S. Juggling type 1 diabetes and pregnancy in rural Australia. Midwifery. 2009;25(2):126-33.

63. Zhu H, Graham D, Teh R-W, Hornbuckle J. Utilisation of preconception care in women with pregestational diabetes in Western Australia. Aust N Z J Obstet Gynaecol. 2012;52(6):593-6.

64. Diabetes and Pregnancy Group. Knowledge about preconception care in French women with type 1 diabetes. Diabetes Metab. 2005;31(5):443-7.

65. Sapiano K, Savona-Ventura C, Calleja-Agius J, Serracino-Inglott A, Azzopardi LM. Attitudes towards preconception care in Maltese women with type 1 diabetes mellitus. Gynecol Endocrinol. 2012;28(12):1006-9.

66. Mortagy I, Kielmann K, Baldeweg SE, Modder J, Pierce MB. Integrating preconception care for women with diabetes into primary care: a qualitative study. Br J Gen Pract. 2010;60(580):815-21.

67. Heslehurst N, Rankin J, Wilkinson J, Summerbell C. A nationally representative study of maternal obesity in England, UK: trends in incidence and demographic inequalities in 619323 births, 1989-2007. Int J Obesity. 2009;34(3):420-8.

68. Kim SY, Dietz PM, England L, Morrow B, Callaghan WM. Trends in Pre-pregnancy Obesity in Nine States, 1993-2003. Obesity. 2007;15(4):986-93.

69. Kain J, Vio F, Albala C. Obesity trends and determinant factors in Latin America. Cad Saude Publica. 2003;19:S77-86.

70. Prentice AM. The emerging epidemic of obesity in developing countries. Int J Epidemiol. 2006;35(1):93-9.

71. Rahman A, Surkan PJ, Cayetano CE, Rwagatare P, Dickson KE. Grand challenges: Integrating maternal mental health into maternal and child health programmes. PLoS Med. 2013;10(5):e1001442.

72. McQuillan J, Greil AL, Shreffler KM. Pregnancy intentions among women who do not try: focusing on women who are okay either way. Matern Child Health J. 2011;15(2):178-87.

73. Janz NK, Herman WH, Becker MP, Charron-Prochownik D, Shayna VL, Lesnick TG, et al. Diabetes and pregnancy: factors associated with seeking pre-conception care. Diabetes Care. 1995;18(2):157-65.

74. Metcalfe A, Williams J, McChesney J, Patten S, Jetté N. Use of complementary and alternative medicine by those with a chronic disease and the general population-results of a national population based survey. BMC Complement Alternat Med. 2010;10(1):58.

75. Lui C-W, Dower J, Donald M, Coll JR. Patterns and determinants of complementary and alternative medicine practitioner use among adults with diabetes in Queensland, Australia. Evid Based Complement Alternat Med. 2012;2012:7. Article ID 659419.

76. Rayner J-A, Willis K, Burgess R. Women's use of complementary and alternative medicine for fertility enhancement: A review of the literature. J Alternat Complement Med. 2011;17(8):685-90.

77. Davern M. Representative sample. In: Lavrakas PJ, editor. Encyclopedia of survey research methods. Sage Publications, Inc.; 2013. p. 721-23. doi:10.4135/9781412963947.n469.

78. Australian longitudinal study on women's health [http://www.alswh.org.au/]

79. Diggle PJ, Heagerty P, Lianh K-Y, Zeger SL. Analysis of Longitudinal Data. 2nd ed. Oxford: Oxford University Press; 2013.

80. Marshall C, Rossman GB. Designing Qualitative Research. California: Sage Publications; 2011

\section{Submit your next manuscript to BioMed Central and take full advantage of:}

- Convenient online submission

- Thorough peer review

- No space constraints or color figure charges

- Immediate publication on acceptance

- Inclusion in PubMed, CAS, Scopus and Google Scholar

- Research which is freely available for redistribution

Submit your manuscript at www.biomedcentral.com/submit 